\title{
Café e design: considerações teóricas sobre a importância do design informacional na embalagem de café
}

\author{
Erika Veras de Castro ${ }^{1}$; \\ Camila dos Santos Vieira 2; \\ David Guilhon ${ }^{3}$; \\ Ester Costa dos Santos ${ }^{4}$;
}

\begin{abstract}
resumo:
Esse artigo apresenta considerações teóricas em relação às embalagens de produtos alimentícios, a identificação do seu conteúdo e a abordagem histórica. Será dada ênfase ao produto café - reconhecidamente um dos mais populares do Brasil, como estudo de caso, onde os assuntos serão discutidos no intuito de compreender e discorrer sobre o aspecto gráfico. Um dos principais objetivos deste trabalho é demonstrar a importância mercadológica das embalagens para os produtos e sua marca onde, a partir de um design bem elaborado, é possível obter um importante recurso de comunicação visual para a atratividade do cliente, o que vai além das funções de contenção, proteção, comunicação e praticidade. E, como elementos de composição visual do design das embalagens, também serão abordados a importância da tipografia e combinação de cores. Por último, serão abordados aspectos relacionados ao marketing, seus atributos e estratégias, como recurso adicional em termos de entrega de valor para satisfazer necessidades e/ou desejos do mercado.
\end{abstract}

palavras-chave:

Espaço reservado para organização do congresso. 


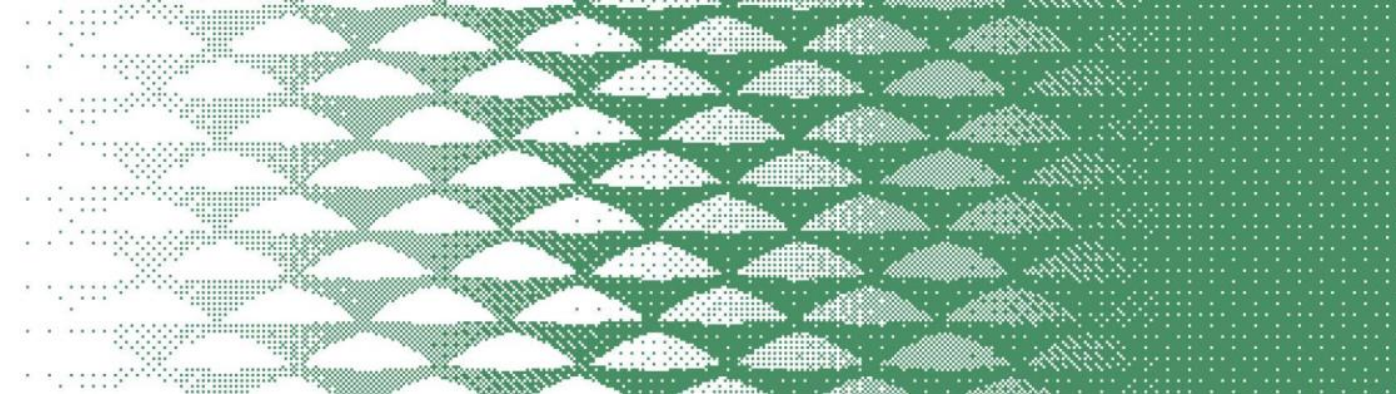

\section{Introdução}

Por volta dos anos 1890 e 1900, observou-se um grande aumento do volume de produtos e, consequentemente, uma maior concorrência, resultando em maior poder de escolha para o consumidor. Essas décadas, até os anos 1930, foram responsáveis pela valorização da marca e da comunicação visual nas embalagens, período denominado de fase ilustrativa (ROMANO, 1996). Houve grande evolução tanto na formação e desenvolvimento de produtos, bem como na questão da visualização do interesse da empresa e do cliente.

A evolução tecnológica vem proporcionando cada vez mais a diversificação das formas de aperfeiçoamento dos produtos, bem como de suas embalagens. Em termos de mercado, a comunicação visual é considerada o fator mais importante para uma empresa e seu produto, pois proporciona, dentre outros, uma atração chamativa com vistas a convencer e até mesmo a persuadir a pessoas a consumirem o que está sendo propagado. Segundo Smith (2005), uma mensagem visual tem um maior poder de informar, educar ou persuadir uma pessoa ou público.

O design pode diferenciar visivelmente um produto ou embalagem. Sendo assim, a efetividade do design contribui para obter a satisfação dos clientes e atingir os objetivos estratégicos da empresa. Esse aspecto é, de fato, um ponto central de um bom planejamento empresarial que busque a diferenciação do seu produto (KOTTLER, 1998). Vale lembrar que cada produto possibilita não apenas uma representação a sua devida empresa, como também conta uma história, podendo ser de um povo, de uma cultura, de uma época, dentre outros. Como por exemplo, temos o café, uma bebida produzida a partir dos grãos torrados do fruto do cafeeiro. Pode ser servido tradicionalmente quente, mas também pode ser consumido gelado, dependendo do local ou gosto do cliente. Esse Artigo possui o objetivo de abordar tais assuntos, discorrendo sobre a importância da comunicação visual proposta em diversas embalagens associadas a variedades de conteúdos distintos, com ênfase no produto café.

\section{O café e seu contexto histórico}

A origem do grão de café surgiu na Africa (SANDALI, 2003), no centro na plantação natural de Kaffa, seguido de uma lenda sobre um pastor, que ao observar um determinado arbusto em seu rebanho, ficou fascinado pelo efeito excitante das folhas e frutos. Quanto mais seus animais consumiam, mais dispostos ficavam. Quando o próprio pastor o provou, gostou muito, e logo encaminhou a novidade à população. A partir daí iniciou-se o consumo por lá e, posteriormente, sua disseminação mundo afora.

Segundo Furtado (2000), o Brasil não era considerado exportador de café até 1820, embora tenha sido o primeiro a exportar café em 1800. A partir da independência do país, começou oficialmente a era do café. Contudo, em 1870, uma grande geada afetou severamente as magníficas plantações nas áreas férteis do oeste de São Paulo, seguida por fortes secas e incêndios, levando o fogo a se espalhar para o Paraná. No entanto, com o desenvolvimento das ferrovias e a abertura de novas áreas, o Café continuou a se desenvolver e logo com o início do desenvolvimento do comércio, veio a chegada das embalagens.

\section{Fatores históricos em relação às embalagens}

De acordo com Lautenschläger (2001), o desenvolvimento de embalagens passou por três fases distintas: a primeira fase, que remonta à origem do homem, até cerca de 4000 A.C, que é caracterizada 


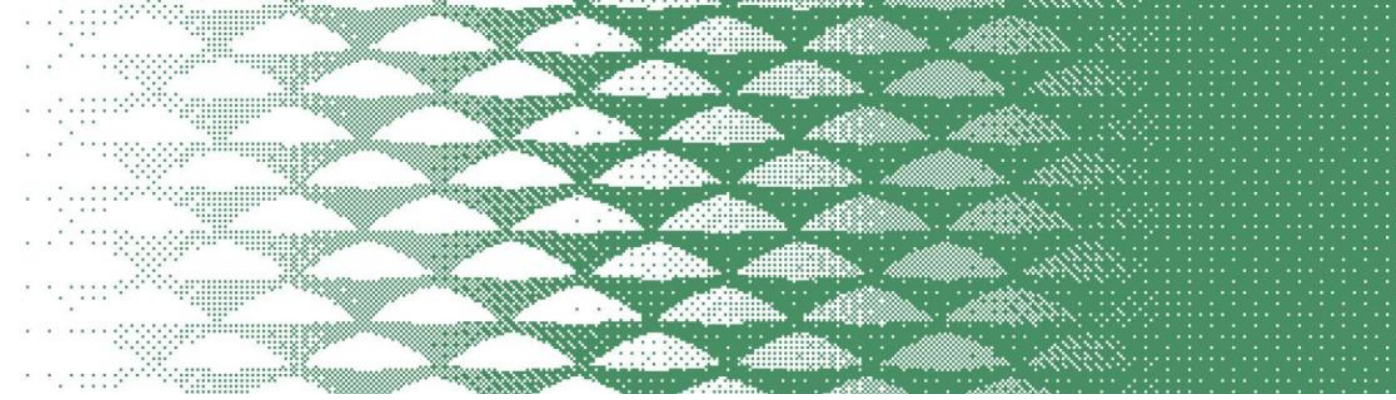

pela natureza: embalagens como conchas, cabaças, folhas e troncos de árvores. A história da segunda etapa remonta a 4000 A.C a cerca de 1760 D.C. é caracterizada pela embalagem manual. Esta deve-se à necessidade de recipientes adequados para as atividades comerciais da época: produtos de vidro, argila, tecidos de fibras naturais, bolsas de couro e muitos outros desenvolvimentos. Segundo Negrão e Camargo (2008), a embalagem surgiu por volta de 2200 a.C. Inicialmente, era utilizada funcionalmente para envolver e proteger o produto, tanto para transporte, quanto para conservação e preservação das características intrínsecas do mesmo.

Até o início do século 20, as cores e a arte das Embalagens estavam completamente ligadas a movimentos artísticos que remetiam à Art Noveau e à Art Déco. Com o surgimento dos autos serviços como supermercados, os produtos necessitavam auto persuadir os consumidores sem ajuda de vendedores; sendo assim, as embalagens passam a ter outras funções, tais quais, informar, identificar e promover serviços e marcas (NEGRÃO e CAMARGO, 2008). No Brasil, o desenvolvimento da embalagem ocorreu a partir de 1808, com a vinda da família real e da corte portuguesa. A permissão de Dom João VI para o funcionamento de fábricas e manufaturas, e a abertura dos portos para negociações amistosas, levou ao surgimento das primeiras fábricas de embalagens no país (ROMANO, 2011).

Na Grã-Bretanha no século 17 , até meados do século 18 , a tecnologia de fabricação de embalagens de vidro e impressão de etiquetas de papel alcançaram um desenvolvimento notável neste campo, contudo poucas inovações foram verificadas. Mas em 1760, inúmeras invenções e melhorias contribuíram para o surgimento desta tecnologia, com a revolução Industrial na Grã-Bretanha. A terceira etapa, de 1760 até o presente, é caracterizada pela embalagem industrial. A partir de daí, há uma série de atividades, como inovação e desenvolvimento de invenções no Reino Unido, registro de patentes, fundações e fusões de fábricas. E, mais tarde os Estados Unidos, houve grande contribuição para o avanço da tecnologia das embalagens, devido à necessidade da produção de gêneros alimentícios. (LAUTENSCHLÄGER, 2001).

Com o passar do tempo, a embalagem passou a ter outros usos, além de proteger e acondicionar os produtos. Também é considerada um importante auxiliar em todas as etapas da comercialização do produto (da comercialização, distribuição ao processamento), comunicação e logomarca do produto (LAUTENSCHLÄGER 2001). E, posteriormente, as embalagens passaram a constituir uma forma importante de comunicação. Ao comprar alimentos ou bebidas do dia a dia, os consumidores em geral baseiam sua decisão de compra nas características extrínsecas do produto e na aparência (FENKO et al., 2010).

O conceito de embalagem hoje em dia é totalmente diferente do que era visto como algo simples. Segundo o Novo Dicionário Aurélio do século XXI, ano de 2010, a palavra embalagem, oriunda do francês emballage é um recipiente ou papel usado para acondicionar mercadorias ou objetos em pacotes, caixas entre outros para proteger o produto de possíveis danos durante sua transportação.

\subsection{Funcionalidades das embalagens}

No cenário atual, é muito complexa a definição de embalagem, podendo variar conforme a sua finalidade. Segundo Cabral (1984), para o consumidor, a embalagem é um meio de atender à demanda do mesmo. No campo da comercialização, esta serve como um meio adicional de atrair consumidores e vender produtos. Para o design, é necessário proteger o produto até que seja consumido, para garantir 


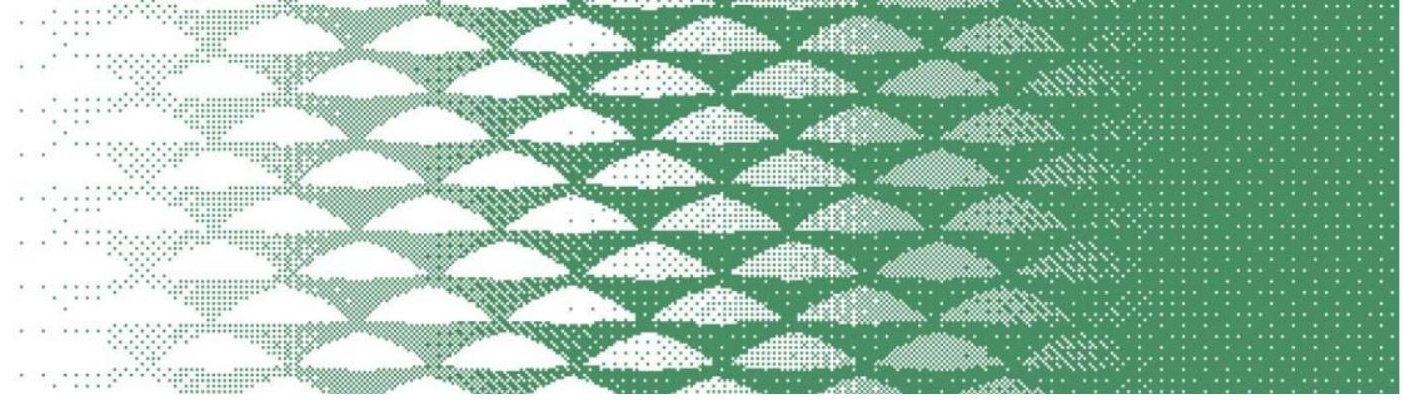

Um exemplo ilustrativo de elemento de tipografia relacionado ao café é a Café Brasil (mostrada na figura 3), uma família de fontes desenvolvida em dois estilos (regular e italic), pela designer Sofia Mohr. Ela projetou esse modelo para representar o nosso café, principalmente para uso em embalagens, títulos de marcas, logotipos e cardápios. Baseado no formato de um grão de café, a fonte Café Brasil possui delicados detalhes e ligaduras que representam o líquido, a espuma e o vapor de uma boa xícara de café (MORH, 2013).

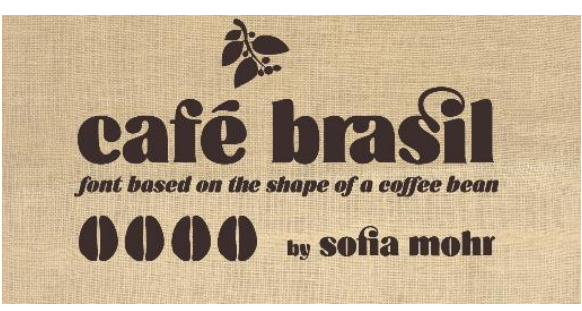

Figura 3 - Fonte Café Brasil

\section{Atributos de marketing}

A embalagem, conforme já mencionado, constituem um elemento importante para atrair a atenção do consumidor e despertar o desejo de compra. E, consequentemente, tornou-se uma importante ferramenta do marketing, contribuindo para a construção de identidade das marcas. Com este enfoque, o projeto de design gráfico de embalagem é desenvolvido considerando principalmente o seu potencial em promover a venda, o que acaba deixando outras atribuições em segundo plano (MESTRINER, 2002).

O marketing pode ser entendido como a arte de explorar, criar e entregar valor para satisfazer necessidades e/ou desejos de um mercado, em relação a produtos, serviços ou ideias a serem consumidos. Sua utilização adequada demanda a adoção de uma estratégia definida que será utilizada nas vendas, comunicações e no desenvolvimento do negócio em geral (GRACIOSO, 1991).

Para Zenvia (2009), o Marketing de Produto é uma das principais vertentes de marketing, na qual uma estratégia é utilizada para definir o posicionamento da marca em relação a um novo produto, bem como formas de divulgar o lançamento ao consumidor. Uma estratégia de marketing de produto é a base para descrever todo o ciclo de um novo produto, desde o desenvolvimento até o lançamento. Essa estratégia serve para descrever público-alvo, persona, posicionamento da marca, canais de divulgação e, após o lançamento, mensurar resultados.

O americano Philip Kotler, considerado o maior especialista em Marketing, popularizou o famoso conceito dos 4 Ps do Marketing, originalmente proposto por Jerome McCarthy. São quatro pilares básicos: Produto, Preço, Praça e Promoção (KOTLER, 1998). Estes são também conhecidos como Mix de Marketing ou Composto de Marketing (MCCARTHY, 1976), e constituem as principais variáveis que uma empresa utiliza para apresentar sua oferta ao público-alvo e alcançar seus objetivos de marketing. São variáveis interdependentes, já que uma tem influência sobre a outra, e depende da outra para o seu sucesso. Devido a isso, precisam ser 
Coffee and design: theoretical considerations about the importance of informational design in coffee packaging

Abstract: This article presents theoretical considerations in relation to food product packaging, the identification of its content and the historical approach. Emphasis will be given to the coffee product admittedly one of the most popular in Brazil, as a case study, where the subjects will be discussed in order to understand and discuss the graphic aspect. One of the main objectives of this work is to demonstrate the marketing importance of packaging for products and their brand where, from a welldesigned design, it is possible to obtain an important visual communication resource for customer attractiveness, which will in addition to the functions of containment, protection, communication and practicality. And, as elements of the visual composition of packaging design, the importance of typography and color combination will also be addressed. Finally, aspects related to marketing, its attributes and strategies will be addressed, as an additional resource in terms of delivering value to satisfy market needs and/or desires.

Keywords: packaging; graphic elements; coffee; typography; color; marketing

\section{Referências bibliográficas}

ANYADIKE, N - Embalagens Flexíveis: São Paulo: Editora Blucher 2009.

CABRAL, A.; et al. Apostila de embalagem para alimentos. Campinas, 1984.

CAETANO, Marcela. Consumo de café no Brasil em 2020 foi o segundo maior da série histórica, 2021. Disponível em: https://valor.globo.com/agronegocios/noticia/2021/03/09

CARVALHO, F. F. Semiótica social e imprensa: o layout da primeira página de jornais portugueses sob o enfoque analítico da gramática visual, Universidade de Lisboa, 2012.

CAVALCANTI, P., CHAGAS, C. História da embalagem no Brasil, São Paulo: Grifo, 2006.

CERVO, A.L.; BUENO, C. História da Política Exterior do Brasil. São Paulo: Editora Ática, 2002.

CLEMENTE, Matheus. Entenda o que é Psicologia das Cores e descubra o significado de cada cor, 2020. Disponível em: https://rockcontent.com/br/blog/psicologia-das-cores/

FARINA, M. et al; Psicodinâmica das cores em comunicação $6^{\circ}$ Edição, São Paulo: Bluncher 2011

FENKO, A., SCHIFFERSTEIN, H.N., HEKKERT, P. Shifts in sensory dominance between various stages of user-product interactions, Appl. Ergon, 2010

FRANCHETTA, A. A importância da tipografia na construção de uma identidade visual, 2015. Disponível em: https://www.estudioroxo.com.br

FINIZOLA, Fátima; FARIAS, Priscila L.; ZIBEL, Carlos Costa (coord). Tipografia Vernacular Urbana - Uma Análise dos Letreiramentos Populares. São Paulo: Blucher, 2010.

FURTADO, C.; Formação Econômica do Brasil. São Paulo: Cia. Editora Nacional, 2000

GARÇÃO, João. A cor fazendo comunicação. Dissertação (Mestrado em Comunicação Social) Universidade Metodista de São Paulo. São Bernardo do Campo: UMESP, 1996.

GRACIOSO, Francisco. "Marketing, uma Experiência Brasileira". São Paulo: Cultrix, 1991 
KOTLER, P. Administração de Marketing: análise, planejamento, implementação e controle. 5 ed. São Paulo: Atlas, 1998.

LAUTENSCHLÄGER, B. I. Avaliação de embalagem de consumo com base nos requisitos ergonômicos informacionais. 2001. Dissertação (Mestrado em Engenharia de Produção). UF Santa Catarina.

LUPTON, E. Pensar com tipos: guia para designers, escritores, editores e estudantes, São Paulo: Cosac Naify, 2013

NEGRÃO, Celso. Design de embalagem: do marketing à produção. São Paulo: Novatec, 2008.

MARCOLINO, Rayane. O cafezinho agora é gourmet, 2014. Disponível em https://www.mundodomarketing.com.br

MARTINS, Ana Luiza. História do café. 2.ed. São Paulo: Contexto, 2012.

MESTRINER, F. Design de embalagem: curso avançado. Paulo: Pearson Prentice Hall, 2007.

MCCARTHY, E. J. Marketing básico: uma visão gerencial. Rio de. Janeiro: Zahar, 1976.

MOURA, R. A.; BANZATO, J. M. Embalagem, unitização e conteinerização. São Paulo, SP: IMAM, 1997.

NARDELLI, Flávio. Curso Viver de Arte, 2020. Disponível em: www.arteemcurso.com.br

NEGRÃO, C.; CAMARGO, E. Design de embalagem: do marketing à produção. São Paulo: Novatec, 2008.

NEVES, C. A História do café. Rio de janeiro, Instituto Brasileiro do Café, 1974.

NEVES, Orlando. Dicionário da origem das palavras. São Paulo: Oficina do Texto, 2012

NUNES, Eduardo. A Evolução do Marketing 1.0, 2.0, 3.0 E 4.0, 2020. Disponível em: https://ettoscomunica.com/a-evolucao-do-marketing/

PASCHOAL, Luiz Noberto. Aroma de Café: Guia prático para apreciadores de café. 2. ed. Campinas: Fundação Educar DPaschoal, 2006.

PEÇANHA, Vitor. 4 Ps do Marketing: entenda tudo sobre o conceito de Mix de Marketing, 2020. Disponível em: https://rockcontent.com/br/blog/4-ps-do-marketing/

RALLO, Rafael. Tipografia: como usar um dos pilares do Design Gráfico a seu favor (2019). Disponível em: https://rockcontent.com/br/blog/tipografia/

SANDALJ, V; Eccardi Fulvio; O café: ambientes e diversidade. Rio de Janeiro: Casa da Palavra, 2003

SMITH, K.L.; Handbook of visual communication: theory, methods, and media. [S.I.]: Routledge, 2005

ZENVIA, Marketing de Produto: o que é, como funciona e 5 dicas para melhorar a estratégia, 2019. Disponível em: https://www.zenvia.com/blog/marketing-de-produto 